Original Research Paper

\title{
Statistical Analysis of Auto Dilution Vs Manual Dilution Process in Inductively Coupled Plasma Spectrometer Tests
}

\author{
Frederick Rich and M. Affan Badar \\ Department of Applied Engineering and Technology Management, \\ Indiana State University, Terre Haute, IN 47809, USA
}

\author{
Article history \\ Received: 13-06-2016 \\ Revised: 17-06-2016 \\ Accepted: 23-06-2016 \\ Corresponding Author: \\ Frederick Rich \\ Indiana State University \\ Terre Haute, IN 47809, USA \\ frich@sycamores.indstate.edu
}

\begin{abstract}
Gregory Poole Equipment Company is the Caterpillar Dealer in eastern North Carolina which sells and services anything that Caterpillar Incorporated manufactures. One value added service provided by this company is fluid analysis. This service consists of 22 separate tests on engine oil, power train lubricants, hydraulic oils, coolants and fuels. One particular test performed in this suite of tests is a plasma spectrometer test which analyzes wear metals in the oil. This test is specifically used to help technicians troubleshoot problems or to assist in scheduling planned maintenance in construction and mining equipment fleets. This particular test is currently the bottleneck in the oil lab and more specifically the dilution sub-process in prepping the oil sample for the plasma spectrometer. To overcome this bottleneck an auto diluter was installed to complement the manual dilution process that is also still in process today. The lab manager questioned if the auto-diluter process is generating the same results as the manual process with regards to the quality control check performed on three different certified known value calibration solutions. This paper analyzes control data results from the two populations of different dilution methods to determine if they are producing the same results.
\end{abstract}

Keywords: Plasma Spectrometer, Analysis of Variance, Sub-Process, Standard, Oil Analysis, Fluid

\section{Introduction}

Gregory Poole Equipment Company is the Caterpillar dealership in eastern North Carolina providing sales and service to the mining, marine engine, electric power and construction machinery industries. This company promotes a comprehensive portfolio of product support offerings that help customer maintain their equipment fleets. One such service is scheduled fluid analysis. Customers provide 6 fluid ounces of lubricating oil, diesel fuel or coolant and the Fluid Analysis Laboratory will perform 22 diagnostic tests on the particular fluid. Some laboratories perform up to 40 tests (Van Rensselar, 2016). The report generated from these tests are very valuable in troubleshooting machine issues and to help plan and maximize maintenance costs. Figure 1 is a copy of the completed report that the equipment owner receives. It shows test results and builds trends from previous tests shown in the two bottom sections. In addition there are specific recommendations given from a highly trained and certified interpreter that reviews the test data and directs a course of action based on the results (Turis and Kucera, 2016). If the report shows a possible issue, the recommendation may be to drain the oil, change the crankcase filter and resample at 100 hours of operation. If there is a major issue, the recommendation could be to shut the machine down and troubleshoot the area that contains the metal that is elevated. If for example the metal molybdenum is trending high in an engine sample, that particular metal is only found in the turbocharger 
bearings. Therefore the technician may inspect bearing end play or perform maintenance on the turbocharger before it fails catastrophically. Data accuracy and proper interpretation of the test results is extremely important. Having inaccurate readings from the instruments could bias the data creating inaccurate measurements. The inaccurate measurements will confound the interpretation of the data resulting in inaccurate recommendations that could cost the customer thousands of dollars.

One of the most important tests performed is the Plasma Spectrometer Test (PST) which analyzes the amount of wear metal in suspension in the oil (Macian et al., 2012). When an engine is operating and under load, very small particles of bearing material or piston cylinder ring material will wear during the normal engine wear process (Kucera et al., 2016; Chen and Tsui, 2013). As the engine wears over time, the parts per million (ppm) of wear metal in the oil should increase and be roughly the same values at the same service interval of say $250 \mathrm{~h}$ of engine operation (Cao et al., 2014). This should remain constant unless there is a change in the operation conditions of the machine. If trends begin to be elevated at the same service meter hour reading there may be a bearing failing or dirt entering the engine causing accelerated wear to the engine components (Bartelmus, 2014). If this information is known early enough, relatively inexpensive maintenance or corrective actions can be taken before a catastrophic failure occurs. It is far less expensive to repair an engine before failure than after the bearing completely fails ruining the crankshaft or other components (Degeratu et al., 2015; Van Rensselar, 2012). Figure 1 shows these trends over time building a history of wear rates on this particular machine the sample was taken from.

The PST is one of the most important and most complex tests performed in generating this report. Its precision and accuracy is critical in making the proper diagnosis for our customers in guiding them through some very large dollar valued decisions. A very important part of the PST is the dilution sub-process (McDowell, 2015). The oil sample being tested must be diluted with kerosene with a one part sample oil to four parts kerosene ratio before the sample trays can be loaded into the PST machine as shown in Fig. 2. This sub process of diluting the sample with kerosene shown by the process maps in Fig. 3 and 4 is the target of study for this paper.

It was found the PST has the longest cycle time of any of the 22 tests performed in the lab and the dilution process was the sub-process that was creating this issue. With customer sample volume growing at a rate of $15 \%$ per year, this issue had to be addressed quickly. For years the lab diluted the oil manually using calibrated pipettes to meter the kerosene into the oil being tested shown in Fig. 5. To speed up this subprocess within the PST an auto-diluter was added to the process to complement the manual process shown in Fig. 6. Now the lab technicians can have the autodiluter working concurrently while they are manually diluting another tray for the PST machine. There are two sample dilution processes.

\begin{tabular}{|c|c|c|c|c|c|c|c|c|c|c|c|c|c|c|c|c|}
\hline Wear Mllebts (ppm) & $\mathrm{Cu}$ & $\mathrm{Fe}$ & $\mathrm{Cr}$ & Al & $\mathrm{Pb}$ & $3 n$ & si & $\mathrm{Ma}$ & K & Mo & Ni & $\mathrm{Ca}$ & $\mathrm{Ng}$ & $2 \mathrm{n}$ & $p$ & Ba \\
\hline D130-46007-4201 & 1 & 4 & 0 & 2 & 0 & 0 & 2 & 2 & 0 & 61 & 0 & 1700 & 330 & 1054 & 800 & 0 \\
\hline D180-46:15-1303 & 0 & 1 & 0 & 0 & 0 & 0 & 2 & 2 & 0 & 58 & 0 & 1663 & 348 & 1137 & 1043 & 0 \\
\hline Dis0-45205-0118 & 0 & 3 & 0 & 0 & 0 & 0 & 2 & 2 & 0 & 85 & 0 & 1281 & 410 & 1277 & 1000 & 0 \\
\hline Dig0-45225-4110 & 0 & 4 & 0 & 0 & 0 & 0 & 2 & 1 & 0 & 60 & 0 & 1966 & 436 & 1244 & 1003 & 0 \\
\hline $\begin{array}{l}\text { Oi Condifion I } \\
\text { Partidte Count (athanl) }\end{array}$ & эт & $0 \times 1$ & Кіт & SUL & & w & A & $\mathbf{F}$ & PFC & viou & & & & & & \\
\hline D150-46:07-4201 & 13 & 12 & 0 & 18 & & $\mathrm{~N}$ & $\mathrm{~N}$ & $\mathrm{~N}$ & 0.37 & 12.5 & & & & & & \\
\hline D180-40815-0303 & 8 & 12 & 0 & 17 & & $\mathrm{~N}$ & N & N & 0.00 & 13.2 & & & & & & \\
\hline Dis0-45205-0118 & 11 & 12 & 0 & 18 & & N & N & N & 0.54 & 13.0 & & & & & & \\
\hline D180-45225-11: & 15 & 12 & 0 & 18 & & $\mathrm{~N}$ & N & $\mathrm{N}$ & 0.58 & 13.4 & & & & & & \\
\hline
\end{tabular}

Fig. 1. Sample of finished sample report 


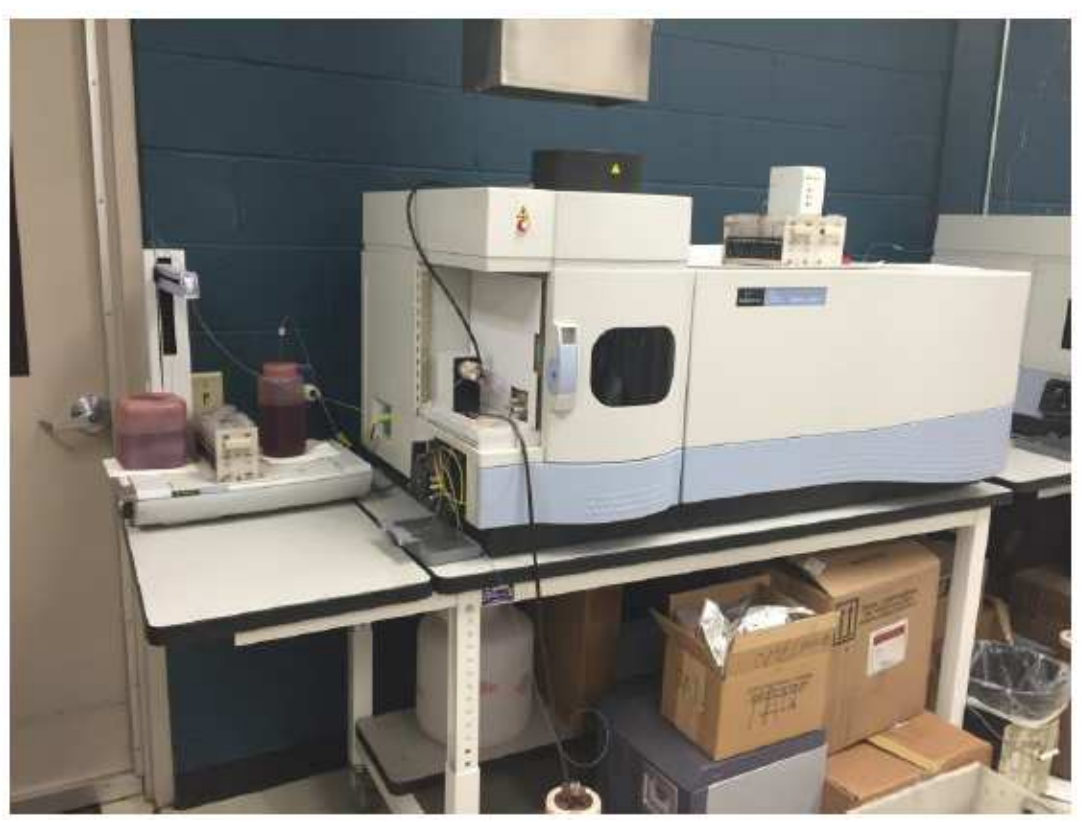

Fig. 2. Inductively coupled plasma spectrometer with sample tray loaded
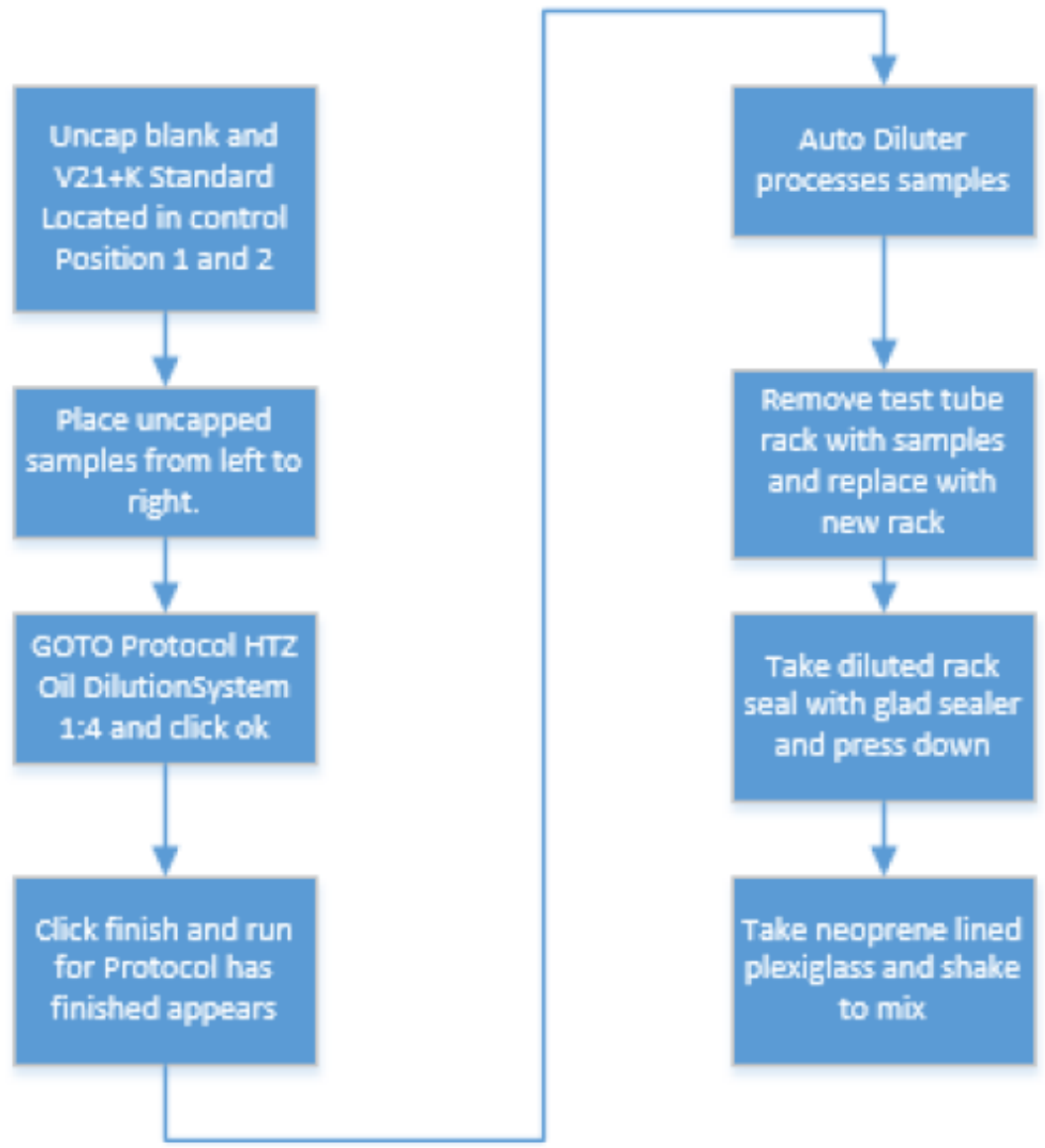

Fig. 3. High level auto dilution process 

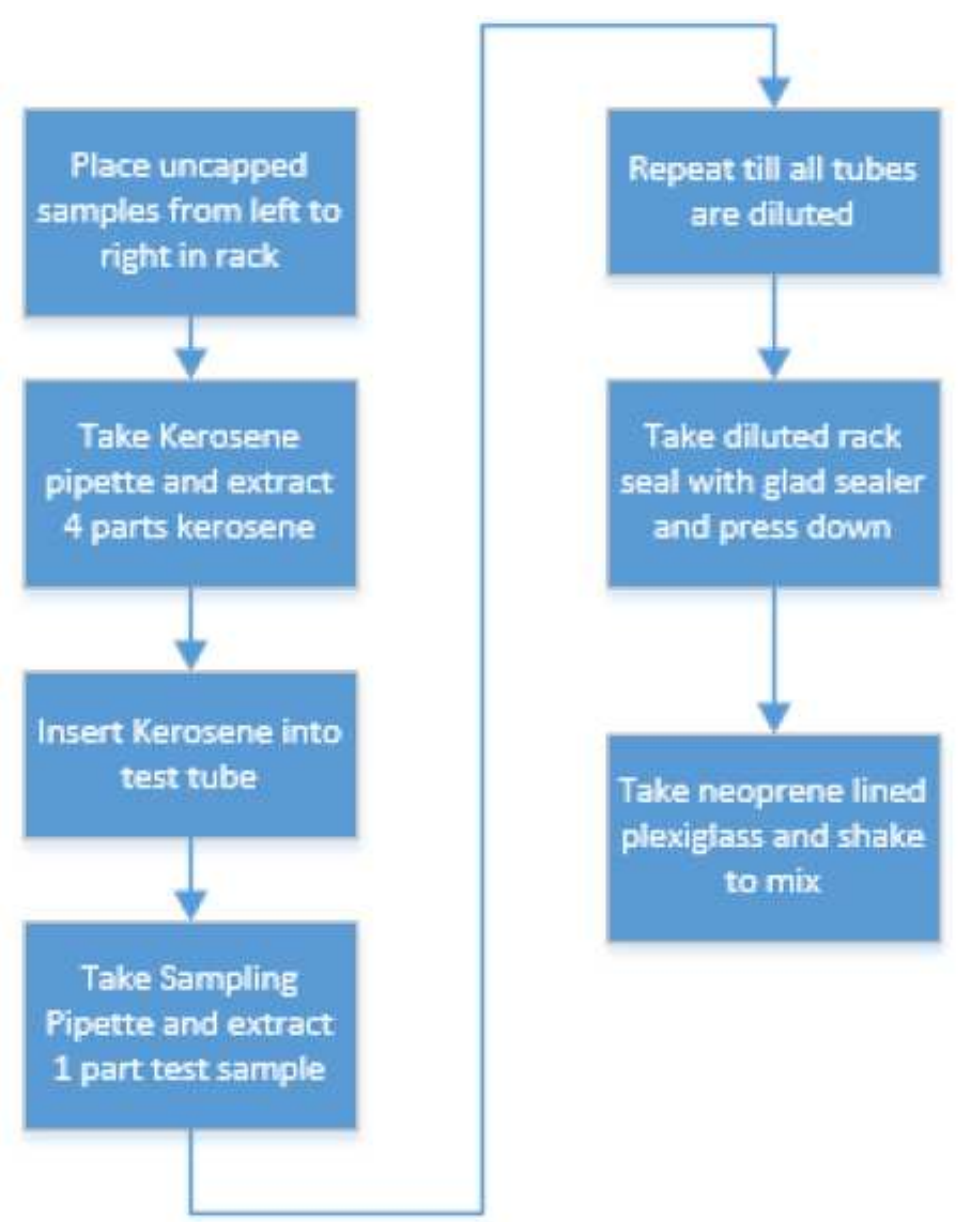

Fig. 4. High level manual dilution process

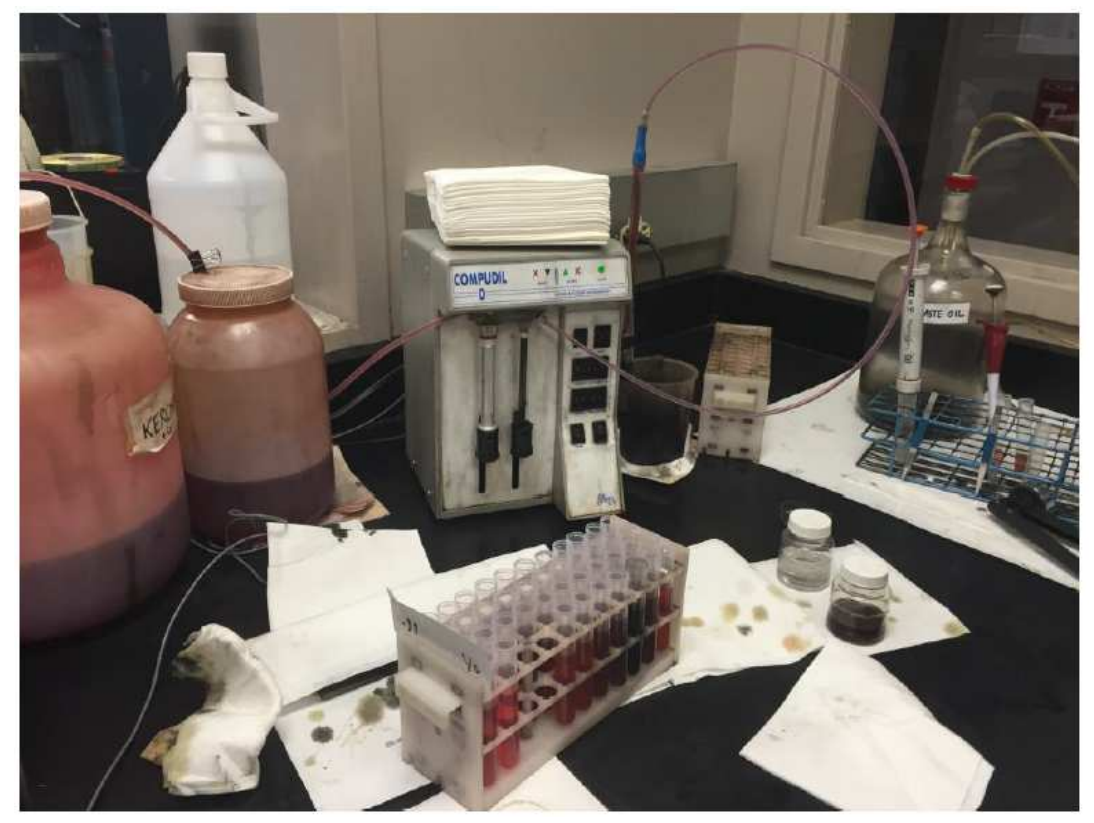

Fig. 5. Manual process of samples being diluted with kerosene 


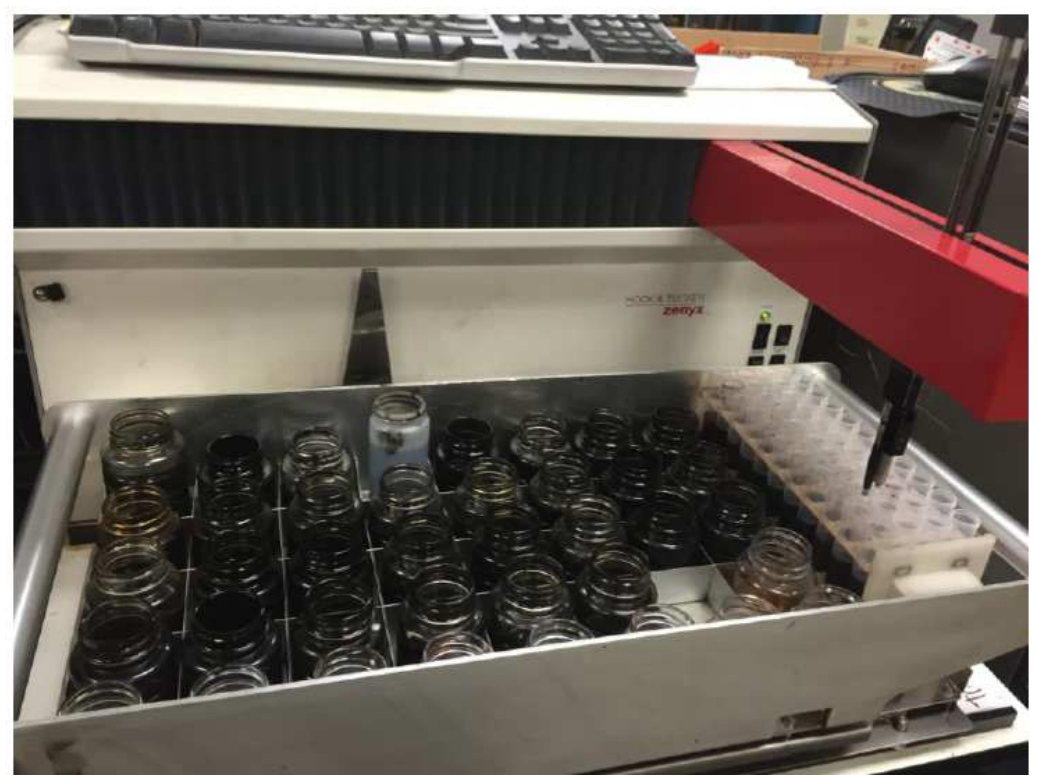

Fig. 6. Auto-dilution process showing samples being diluted with kerosene

\section{Problem Statement}

The lab manager was very concerned that having two dilution processes could bring bias or some unforeseen variation into the results of the PST. It was requested that a formal investigation be initiated to determine if indeed there was differences in the results of the manual and automated dilution sub-processes. An additional concern that was uncovered from the initial analysis was to determine if there is variation being generated by the different laboratory technicians performing the manual dilution process.

\section{Research Questions}

- Are there differences in the mean values between the manual dilution process sample and the autodilution sample for each of the three metal known quality control standards?

- Are there differences in the mean values between the lab technician results in manual dilution process for each of the three metal known quality control standards?

\section{Hypotheses}

The null hypothesis for research question (RQ) 1 states:

- Ho: $\mu$ auto-dilute $=\mu$ manual-dilute

- $\quad$ Ha: $\mu$ auto-dilute $\neq \mu$ manual-dilute

The null hypothesis for RQ 2 states:

- Ho: $\mu$ technician $1=\mu$ technician $2=\mu$ technician $3=$ $\mu$ technician 4
- $\quad$ Ha: $\mu$ technician $1 \neq \mu$ technician $2 \neq \mu$ technician $3 \neq$ $\mu$ technician 4

\section{Method}

To test these hypotheses, quality control data were used from the daily work of the lab technicians. Every day there are on average 8 trays of samples of 48 samples per tray prepared and ran through the PST process. Figure 6 shows the auto-dilution process and how the samples are placed in the trays and diluted with kerosene while Fig. 5 shows the manual version of the same sub-process. In each tray there are three control samples containing a known standard of oil with 100 PPM each of iron $(\mathrm{Fe})$, sodium $(\mathrm{Na})$ and zinc $(\mathrm{Zn})$. These three control standard samples are introduced into the PST instrument as shown in Fig. 2 and the output recorded in ppm. Table 1 shows a sample of this output data in order to understand the file layout. For each tray the method of dilution is noted in the comment column allowing differentiation between the two dilution sub-process methods used. The output data of the standard output measurement is noted in the three results columns highlighted in green. The data collection process took about 1.5 months to accumulate with multiple technicians preforming the tests due to operational necessity. For the technician comparison, the run by column will identify the technician that diluted the samples.

Figure 7-9 are the residual plots from the data for each of the metal standards being tested. The three probability plots show three data sets that appear to be normal for the residuals, except for a couple of outliers, adhere rather closely to the probability line with little deviation. 


\section{Normal Probability Plot}

(response is Fe Results (ppm))

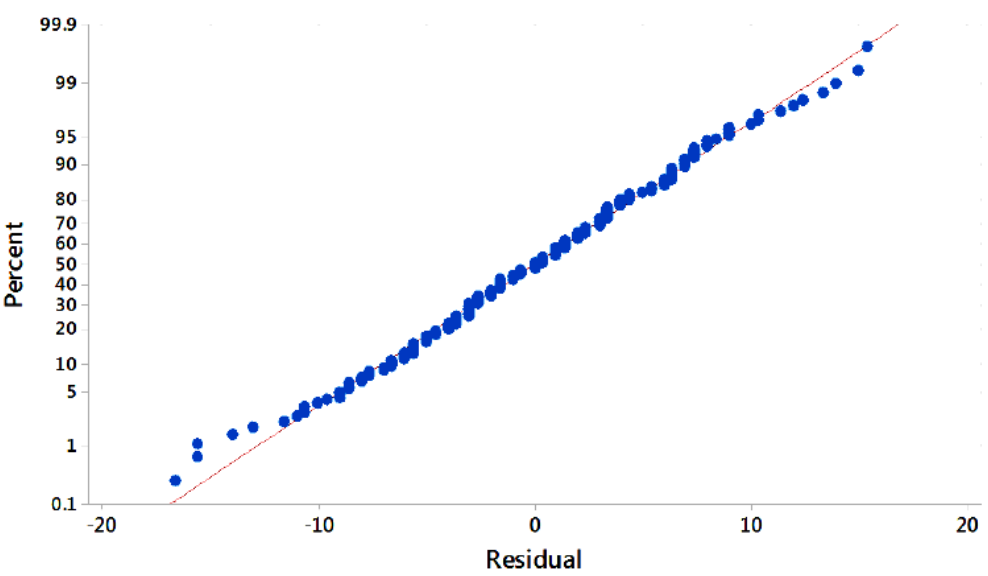

Fig. 7. Probability plot of Fe residuals

Normal Probability Plot (response is $\mathrm{Na}$ Results (ppm))

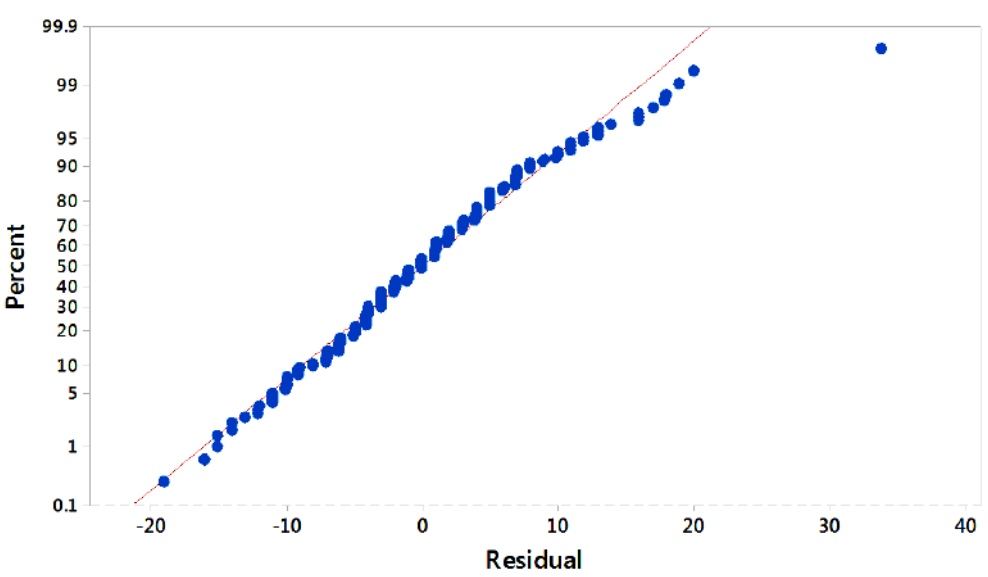

Fig. 8. Probability plot of Na residuals

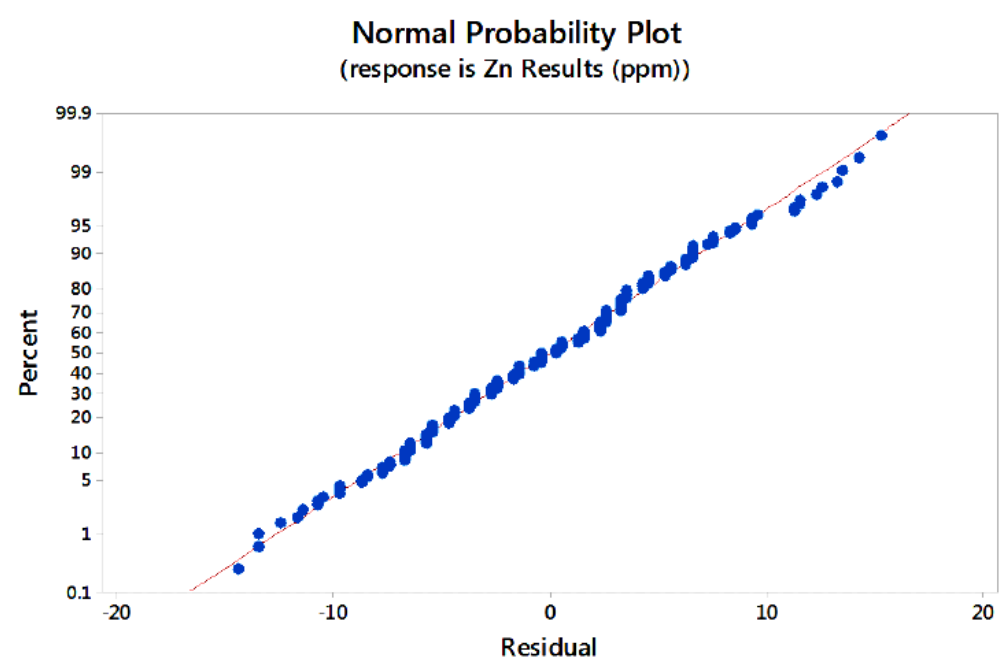

Fig. 9. Probability plot of $\mathrm{Zn}$ residuals 
Frederick Rich and M. Affan Badar / American Journal of Engineering and Applied Sciences 2016, 9 (3): 611.624 DOI: 10.3844/ajeassp.2016.611.624

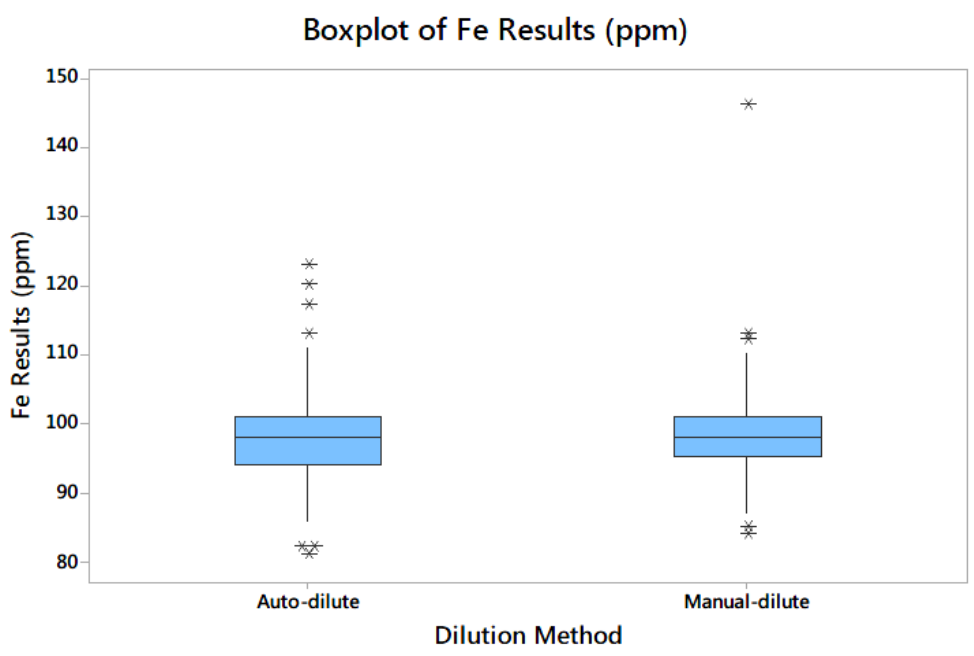

Fig. 10. Boxplot of Fe results

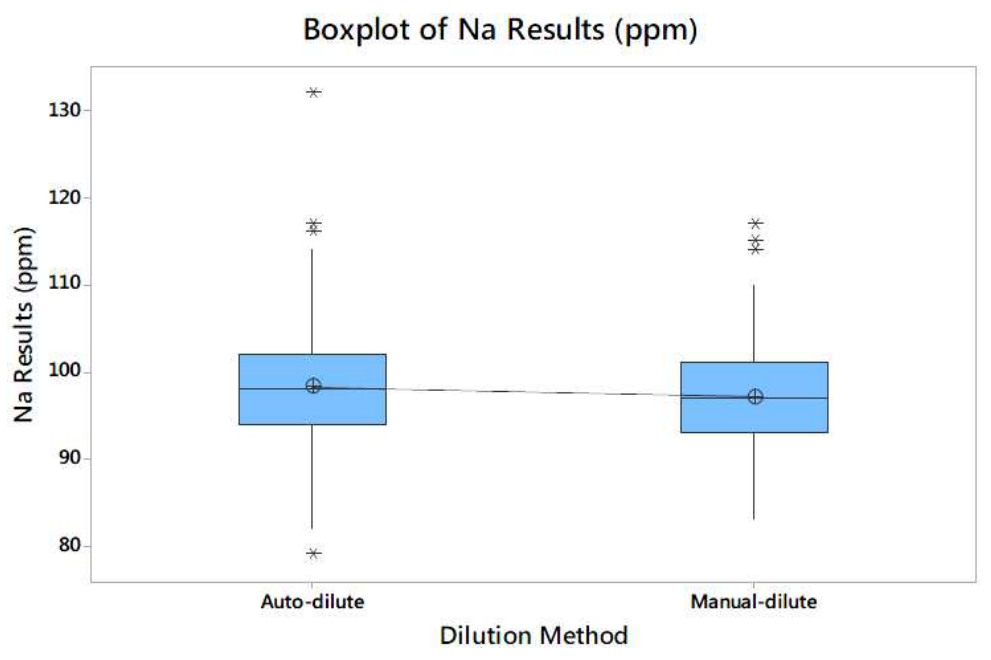

Fig. 11. Boxplot of Na results

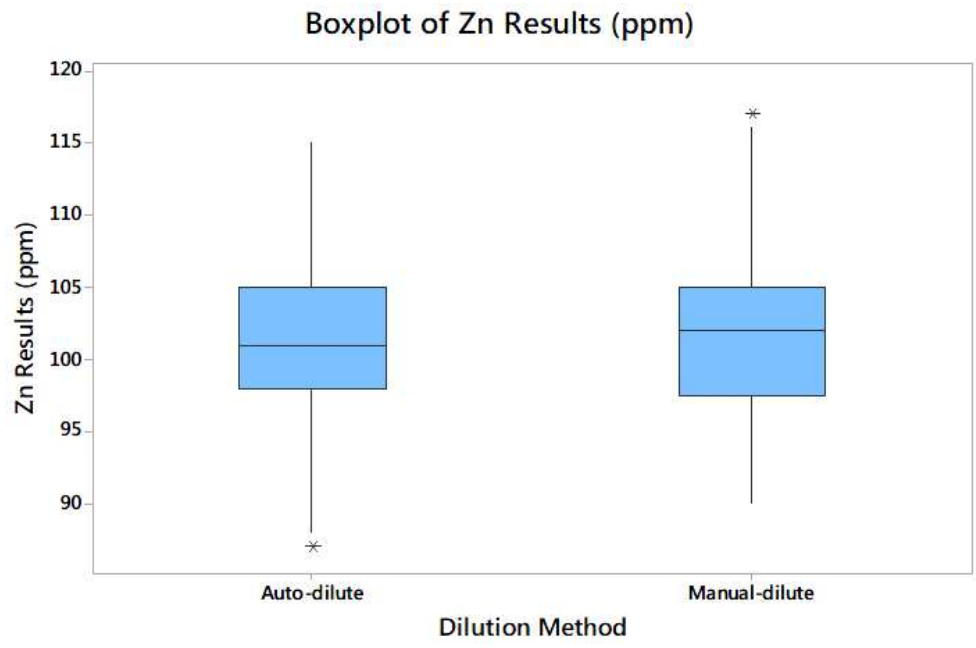

Fig. 12. Boxplot of $\mathrm{Zn}$ results 


\begin{tabular}{|c|c|c|c|c|c|c|c|}
\hline 208 & & bl50 & 92 & 95 & 98 & $\mathrm{mkn}$ & Auto-dilute \\
\hline 209 & & bl52 & 96 & 95 & 99 & $\mathrm{mkn}$ & Auto-dilute \\
\hline 210 & & gp7,23 & 94 & 94 & 98 & $\mathrm{mkn}$ & Manual-dilute \\
\hline 211 & & g4 & 96 & 95 & 98 & rjb & Auto-dilute \\
\hline 212 & & g5 & 81 & 79 & 95 & $\mathrm{rjb}$ & Auto-dilute \\
\hline 213 & & $\operatorname{ct} 36$ & 92 & 89 & 97 & $\mathrm{cmw}$ & Auto-dilute \\
\hline 214 & & gp6 & 100 & 109 & 93 & www & Auto-dilute \\
\hline 215 & & bl53,35b & 117 & 96 & 104 & $\mathrm{mkn}$ & Auto-dilute \\
\hline 216 & $3 / 18 / 2016$ & gp2 & 98 & 99 & 98 & $\mathrm{mkn}$ & Manual-dilute \\
\hline 217 & & gp1 & 93 & 94 & 94 & $\mathrm{mkn}$ & Manual-dilute \\
\hline 218 & & $\operatorname{ct} 30,40$ & 95 & 94 & 101 & $\mathrm{mkn}$ & Auto-dilute \\
\hline 219 & & $\operatorname{ct3} 1$ & 102 & 103 & 107 & $\mathrm{mkn}$ & Auto-dilute \\
\hline 220 & & $\operatorname{ct} 32$ & 111 & 110 & 113 & $\mathrm{mkn}$ & Auto-dilute \\
\hline
\end{tabular}

Table 2. One way ANOVA for Fe Vs dilution method

One-way ANOVA: Fe Results (ppm) versus dilution method

Method

Null hypothesis

All means are equal

Alternative hypothesis

Significance level

At least one mean is different

Equal variances were assumed for the analysis.

Factor Information

Factor

Levels

2

Analysis of Variance

Source

Dilution method

Error 277

Total

$$
278
$$

Model Summary

$\mathrm{S}$

6.56672

Means

Dilution method

Auto-dilute

Manual-dilute

Pooled StDev $=6.56672$

Fisher Pairwise Comparisons

Grouping Information using the fisher LSD method and 95\% confidence

\begin{tabular}{llll} 
Dilution method & $\mathrm{N}$ & Mean & Grouping \\
Manual-dilute & 129 & 98.411 & A \\
Auto-dilute & 150 & 98.100 & A \\
\hline
\end{tabular}

The heart of this analysis is the analysis of variance test or ANOVA. For each of the three metal quality control runs the population of manually diluted samples is compared to the population of the auto-diluted samples. Table 2-4 show the outputs of these tests with the P-values and F-statistics needed to make decisions on the acceptance of the hypothesis. Table 5 summarizes the outputs for easier interpretation. In addition these tests are graphically depicted by box plots in Fig. 10-12. To reinforce these results by metal control, all data points were combined into one data set and a two sample t-test was performed. Table 6 shows the results from this test along with the box plot in Fig. 13.
The second part of this analysis is to determine whether different technicians impact the output variation of the manual dilution process. It should be noted that four different laboratory technicians perform this work due to operational constraints and work scheduling. The initials of the technician that performed the quality control check are noted in the run by column of Table 1. ANOVA was performed for each of the three metals quality control data to determine if the lab technician was driving any variation between the sampling results. Table 7 to 9 reflect the ANOVA output of this analysis with Table 10 summarizing it into one table for easier interpretation. The graphical representation using boxplots of the variation between technicians is shown Fig. 14. 
Table 3. One way ANOVA for Na Vs dilution method

One-way ANOVA: Na results (ppm) versus dilution method

Method

Null hypothesis

All means are equal

Alternative hypothesis

Significance level

At least one mean is different

Equal variances were assumed for the analysis.

Factor Information

Factor

Levels

2

Analysis of Variance

Source

DF Adj SS

Dilution Method 1

Error $\quad 277$

Total

277
278

Model Summary

$\mathrm{S}$

6.88536

Means

Dilution Method

Auto-dilute

Manual-dilute

\section{R-sq}

$0.62 \%$

\section{$\mathrm{N}$}

150

Pooled StDev $=6.88536$

129

Fisher Pairwise Comparisons

Grouping Information using the fisher LSD method and 95\% confidence

Dilution method

Auto-dilute

Manual-dilute

150

129

Mean

98.167

97.078

Means that do not share a letter are significantly different.

\section{3}

13132.1

13214.3

Values

R-sq(adj)

$0.26 \%$

Mean

98.167

97.078

7.419

6.207

Adj MS

82.27

47.41

F-Value

1.74

P-Value

0.189

$(97.060,99.273)$

$(95.884,98.271)$

Table 4. One way ANOVA for Zn Vs dilution method

One-way ANOVA: $\mathrm{Zn}$ results (ppm) versus dilution method

Method

Null hypothesis

All means are equal

Alternative hypothesis

At least one mean is different

Significance level

$\alpha=0.05$

Equal variances were assumed for the analysis.

Factor Information

Factor Levels Values

Dilution Method 2 Auto-dilute, Manual-dilute

Analysis of Variance

Source

DF Adj SS

4.76

Adj MS

F-Value

P-Value

Dilution method 1

Error $\quad 277$

8024.84

Total

$$
278
$$

8029.60

4.761

0.16

0.685

Model Summary

$\mathrm{S}$

R-sq(adj)

28.971

Grouping

A

A

\subsection{3}

\section{R-sq}

Means

Dilution method

$0.06 \%$

$0.00 \%$

R-sq(pred)

Auto-dilute

\section{N}

Manual-dilute

150

Mean

101.467

$0.00 \%$

Pooled StDev $=5.38243$

129

101.729

StDev

5.209

$95 \%$ CI

(100.602, 102.332)

(100.796, 102.662)

Fisher Pairwise Comparisons

Grouping Information using the fisher LSD method and 95\% confidence

$\begin{array}{llll}\text { Dilution method } & \mathrm{N} & \text { Mean } & \text { Grouping } \\ \text { Manual-dilute } & 129 & 101.729 & \text { A } \\ \text { Auto-dilute } & 150 & 101.467 & \text { A }\end{array}$

Means that do not share a letter are significantly different. 
Frederick Rich and M. Affan Badar / American Journal of Engineering and Applied Sciences 2016, 9 (3): 611.624 DOI: 10.3844/ajeassp.2016.611.624

Table 5. Summary table for ANOVA dilution method by metal

\begin{tabular}{llllll}
\hline Metal Control Standard & Adj SS & Adj MS & F-Value & P-Value & Fisher Pairwise \\
\hline $\mathrm{Fe}$ & 6.70 & 6.702 & 0.16 & 0.694 & A,A \\
$\mathrm{Na}$ & 8.30 & 82.770 & 1.74 & 0.189 & A,A \\
$\mathrm{Zn}$ & 4.76 & 4.761 & 0.16 & 0.685 & A,A \\
\hline
\end{tabular}

Table 6. Two sample $\mathrm{T}$ test for combined date comparing dilution method

Two-sample T-test and CI: Combined, dilution combined

Two-sample T for combined

Dilution combined

Auto-dilute $\quad 450$

$\mathrm{N} \quad$ Mean

99.24

StDev

SE mean

Manual-dilute

387

99.07

6.57

0.31

Difference $=\mu$ (Auto-dilute) $-\mu$ (Manual-dilute)

6.50

0.33

Estimate for difference: 0.172

$95 \%$ CI for difference: $(-0.717,1.061)$

$\mathrm{T}$-Test of difference $=0(\mathrm{Vs} \neq): \mathrm{T}-$ Value $=0.38 \mathrm{P}-$ Value $=0.704 \mathrm{DF}=818$

Table 7. One way ANOVA for $\mathrm{Zn}$ by technician

One-way ANOVA: Zn man versus tech man

Method

Null hypothesis All means are equal

Alternative hypothesis At least one mean is different

Significance level $\quad \alpha=0.05$

Equal variances were assumed for the analysis.

Factor Information

Factor

Levels

4

Tech man

Analysis of Variance

Source

Tech man

DF

Error

3

Total

125

128

R-sq

$\mathrm{S}$

5.57371

$2.47 \%$

Means

Tech

man N

cmw 2

mkn 94

rjb 26

www

26
7

Mean

01.50

101.628

101.15

105.29

Adj SS

98.22

3883.28

3981.50

Pooled StDev $=5.57371$

Fisher Pairwise Comparisons

Grouping information using the fisher LSD Method and 95\% Confidence

Tech

man

www

mkn

$\mathrm{cmw}$

rjb

N
7
94
26

Mean

105.29

101.628

101.50

101.15

Means that do not share a letter are significantly different.

$\begin{array}{lll}\text { Adj MS } & \text { F-Value } & \text { P-Value } \\ 32.74 & 1.05 & 0.371\end{array}$

31.07

R-sq(pred)

$0.00 \%$

StDev

95\% CI

2.12

5.406

(93.70, 109.30)

(100.490, 102.765)

(98.99, 103.32)

$6.50 \quad(101.12,109.46)$ 
Table 8. One Way ANOVA for Na by technician

One-way ANOVA: Na man versus Tech man

Method

Null hypothesis

All means are equal

Alternative hypothesis

At least one mean is different

Significance level $\alpha=0.05$

Equal variances were assumed for the analysis.

Factor Information

Factor

Levels

4

Tech man

Analysis of Variance

Source

DF

Tech man

3

Error

125

Total

128

R-sq

$\mathrm{S}$

6.06340

$6.81 \%$

Means

Tech

man

$\mathrm{cmw}$

mkn

rjb

www

Pooled StDev $=6.06340$

Fisher Pairwise Comparisons

Grouping Information Using the Fisher LSD Method and 95\% Confidence

Tech

man

www

rjb

$\mathrm{mkn}$

$\mathrm{cmw}$

$\mathrm{N}$

2

94

26

7

Mean

94.50

96.500

97.65

103.43

Adj SS

335.6

4595.6

4931.2

R-sq(adj)

$4.57 \%$

Adj MS

111.88

F-Value

3.04

P-Value

36.76

R-sq(pred)

$1.26 \%$

StDev

95\% CI

3.54

6.097

5.93

6.43

(86.01, 102.99)

$(95.262,97.738)$

$(95.30,100.01)$

(98.89, 107.96)

Means that do not share a letter are significantly different.

\section{Boxplot of Combined Data by Dilution Method}

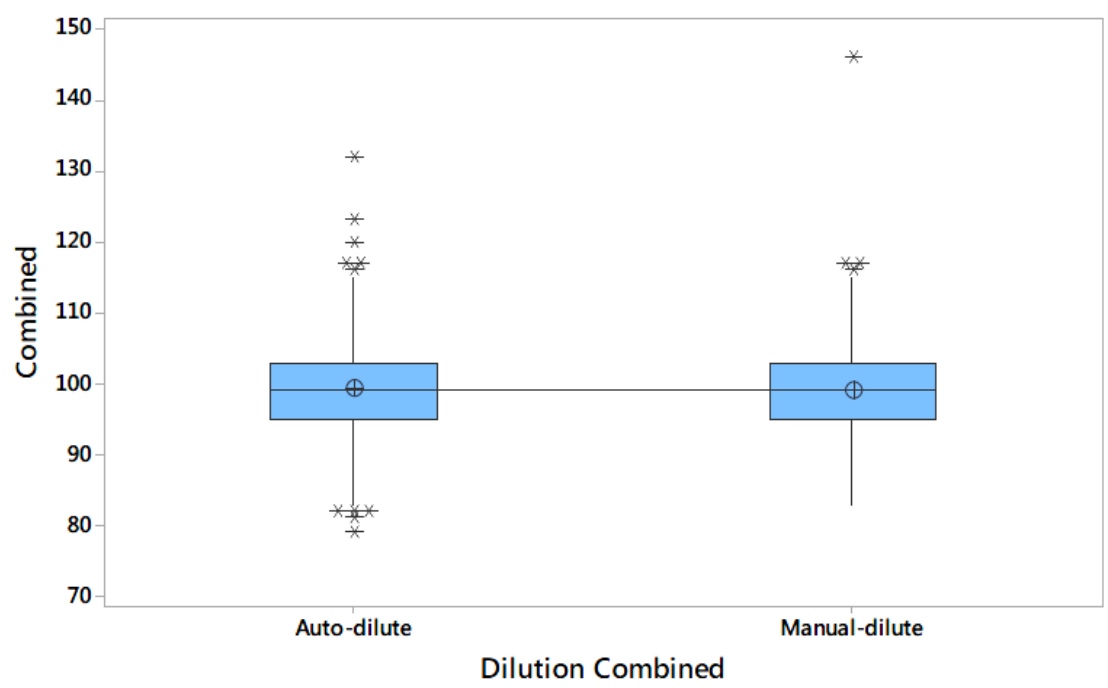

Fig. 13. Boxplot of combined data by dilution method 


\section{Boxplot of $\mathrm{Fe}, \mathrm{Na}, \mathrm{Zn}$ With Manual Dilution}

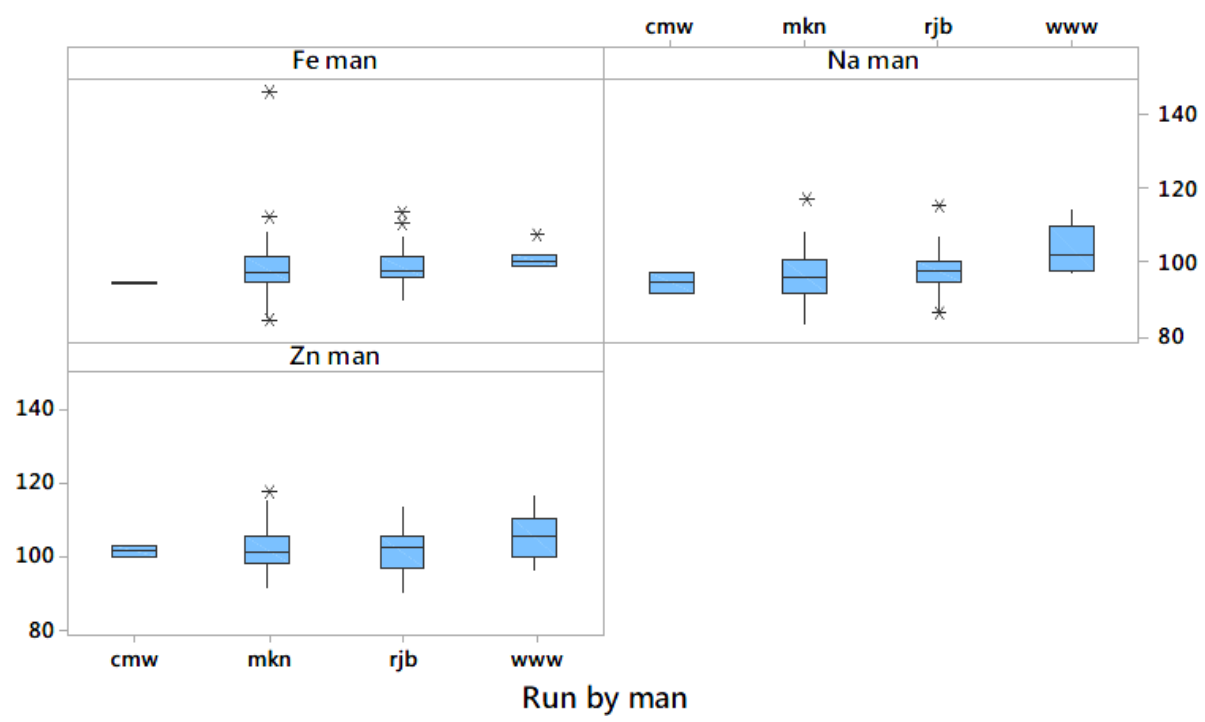

Fig. 14. Boxplot of test metal by run by

Table 9. One Way ANOVA for Fe by technician

One-way ANOVA: Fe man versus Tech man

Method

Null hypothesis

All means are equal

Alternative hypothesis At least one mean is different

Significance level $\quad \alpha=0.05$

Equal variances were assumed for the analysis.

Factor Information

Factor

Tech man

Levels

Values

Analysis of Variance

Source D

Tech man 3

Error 125

Total 128

4

cmw, mkn, rjb, www

Model Summary

$\mathrm{S}$

6.82204

R-sq

$1.65 \%$

Adj SS

97.70

5817.52

Adj MS

5915.22

Means

Tech

man

$\mathrm{N}$

R-sq(adj)

46.54

F-Value

0.70

P-Value

8

R-sq(adj)

R-sq(pred)

$0.00 \%$

$0.00 \%$

$\begin{array}{ll}\text { Mean } & \text { StDev } \\ 94.500 & 0.707 \\ 98.138 & 7.346 \\ 98.96 & 5.48 \\ 101.14 & 2.7\end{array}$

$95 \% \mathrm{CI}$

cmw 2

mkn 94

rjb 26

101.14

2.7

$(84.953,104.047)$

$(96.746,99.531)$

$(96.31,101.61)$

Pooled StDev $=6.82204$

Fisher Pairwise Comparisons

Grouping Information Using the Fisher LSD Method and 95\% Confidence

Tech

man

www

rjb

mkn

cmw

$\mathrm{N}$

Mean

101.14

98.96

98.138

94.500

$(96.04,106.25)$

Means that do not share a letter are significantly different.

Grouping
A
A
A
A


Table 10. Summary of ANOVA table for manual dilution by technician

\begin{tabular}{lcclll}
\hline Metal Control Standard & Adj SS & Adj MS & F-Value & P-Value & Fisher Pairwise Comparison \\
\hline $\mathrm{Fe}$ & 97.70 & 32.57 & 0.70 & 0.5540 & A,A,A,A \\
$\mathrm{Na}$ & 335.60 & 111.88 & 3.04 & 0.0310 & A,B,B,AB \\
$\mathrm{Zn}$ & 98.22 & 32.76 & 1.05 & 0.0371 & A,A,A,A \\
\hline
\end{tabular}

\section{Results}

When looking at the comparison of auto-dilution and manual dilution data analysis it is found that the P-values for each of the three metals control data above the 0.05 alpha. The Sodium (Na) P-value was the lowest at 0.189 with iron at 0.694 and zinc at 0.685 . This tells us to accept the null that the means of the three control output data sets are the same. When looking at the box plots it is evident graphically that there is very little difference in the two methods of dilution. Based on the P-values it should make no difference in the outcomes of the oil analysis if either the manual or auto-dilution sub-process is used in performing the PST test.

The two sample T-test of the combined data results are also resounding. The P-value for this test is 0.704 and a corresponding T-value of 0.38 which again shows that the null hypothesis that the mean values of the data from the two dilution methods are the same.

With regards to the difference of the output data means by technician there are some interesting findings. The P-values for zinc is 0.371 , iron is 0.554 and most interesting sodium is 0.031 . This $\mathrm{P}$-value indicates there is a difference in the sodium test means therefore one must reject the null hypothesis in this case only. There is a low P-value and a difference of the means when looking specifically at the manual dilution process depending on which technician is performing the test. However there is a very low number of data points for two of the lab technicians in making this determination and caution should be used and more data is needed to make a firm decision.

\section{Discussion}

From the results it appears that no matter which metal control is being tested, there is no difference in the mean results when comparing manual and auto dilution methods. It does appear there is enough data points in both categories to make this test valid and currently both process are being utilized daily. As mentioned earlier this sub-process is a bottleneck in the entire PST process for the auto-diluter needs an additional $20 \%$ capacity to satisfy demand. As business levels continue to grow so will this capacity deficit. Knowing that there is no difference in the dilution process gives our Lab Manager some confidence that his lab can continue to utilize both methods with confidence. This knowledge will aid the Laboratory Manager with some operational decisions within the oil lab. There are new auto-diluters available in the marketplace that are much faster than our current model at a cost of $\$ 148,000.00$. These results will assist the manager in deciding if he will continue to utilize manpower with the manual method or purchase the new faster auto-diluter. The manager now knows either method will work and give consistent results.

When looking at the manual process with different technicians, the means do vary by the technician performing the test. It should be noted however that the technician results that were different had a relatively small number of data points to draw from. If there was one improvement to this analysis it would be to have more data points from technicians www and cmw. Even with the low number of data points, more learning could possibly be gained from additional experimentation into why these two technicians have higher readings for the sodium metal test. Given the small number of data point along with the consistency of the other tests, it would be interesting to find out too why only sodium shows this difference between technicians.

Other suggestion for future experimentation would be to perform this same analysis using a different spectrometer in order to see if the results are reproducible (Levinsohn, 1984) and to determine if the brand of oil being analyzed impacts the results of these tests (Markova et al., 2014).

\section{Conclusion}

It can be decided that one must accept the null hypothesis that the mean values of both dilution processes are the same for all three sets of metal quality control data studied. The lab manager can with confidence use both methods to dilute the oil samples and not worry about the outcomes generated by either sub-process. With this new found information the management can make better decisions regarding the future of capital expenditures for lab growth and how to better manage the processes dealing with the PST.

It was also found, with very limited data, that there may be differences within the manual dilution data subset of sodium between technicians. In this case we must reject the null hypothesis for the metal sodium only and accept the null for iron and zinc. There should be further research in this area and more data points gathered to first validate the results with adequate data. It should also be determined why only one of the three metal data subsets had this result. Is this an anomaly or is there truly a difference in the means of the output by technician. 


\section{Author's Contributions}

Frederick Rich: This work was complete as a requirement for a project in the course COT703 advanced statistical analysis at Indiana State University.

M. Affan Badar: Ensured the analysis was performed and interpreted correctly. The project work was revised by both the authors in order to match the style of the journal article.

\section{Ethics}

This article is original and contains unpublished material. The corresponding author confirms that all of the other authors have read and approved the manuscript and no ethical issues involved.

\section{References}

Bartelmus, W., 2014. New focus on gearbox condition monitoring for failure prevention technology. Key Eng. Mater., 588: 184-191.

DOI: 10.4028/www.scientific.net/KEM.588.184

Cao, W., W. Chen, G. Dong, J. Wu and Y. Xie, 2014. Wear condition monitoring and working pattern recognition of piston rings and cylinder liners using on-line visual ferrograph. Tribol. Trans., 57: 690-699. DOI: $10.1080 / 10402004.2014 .906693$

Chen, N. and K.L. Tsui, 2013. Condition monitoring and remaining useful life prediction using degradation signals: Revisited. IIE Trans., 45: 939-952. DOI: 10.1080/0740817X.2012.706376

Degeratu, S., P. Rotaru, S. Rizescu, S. Danoiu and N.G. Bizdoaca et al., 2015. Condition monitoring of transformer oil using thermal analysis and other techniques. J. Thermal Anal. Calorim., 119: 1679-1692. DOI: 10.1007/s10973-014-4276-3
Kucera, M., Z. Ales, J. Pavlu and M. Hnilicova, 2016. Applying of automatic laser particle counter as technique to morphology assessment and distribution of wear particles during lifetime of transmission oils. Key Eng. Mater., 669: 417-425. DOI: 10.4028/www.scientific.net/KEM.669.417

Levinsohn, H., 1984. Limitations of atomic absorption spectrophotometry applied to spectrometric oil analysis. Tribol. Trans., 27: 24-32.

DOI: $10.1080 / 05698198408981541$

Macian, V., B. Tormos, A. Gomez and J.M. Salavert, 2012. Proposal of an FTIR methodology to monitor oxidation level in used engine oils: Effects of thermal degradation and fuel dilution. Tribol. Trans., 55: 872-882. DOI: 10.1080/10402004.2012.721921

Markova, L.V., V.M. Makarenko and M.S. Semenyuk, 2014. A quick lube oil and transformer oil quality monitoring method. Chem. Technol. Fuels Oils, 49: 537-544. DOI: $10.1007 / \mathrm{s} 10553-014-0481-9$

McDowell, R.D., 2015. How do you prepare reference standards and solutions? Spectroscopy, 30: 14-16.

Turis, J. and M. Kucera, 2016. Analysis of oil chargeinstrument of the production line wear regime prediction. Key Eng. Mater., 669: 467-476. DOI: 10.4028/www.scientific.net/KEM.669.467

Van Rensselar, J., 2012. Used oil analysis for predictive maintenance. Tribol. Lubricat. Technol.

Van Rensselar, J., 2016. Unraveling the mystery of oil analysis flagging limits. Tribol. Lubricat. Technol., 72: 33-42. 